\title{
Variabilidade espacial e temporal da vegetação em pastos de capim- braquiária diferidos
}

\section{Manoel Eduardo Rozalino Santos ${ }^{1}$, Dilermando Miranda da Fonseca ${ }^{2}$, Eric Márcio Balbino ${ }^{1}$, Simone Pedro da Silva ${ }^{1}$, João Paulo Ismério dos Santos Monnerat ${ }^{1}$}

\footnotetext{
1 Doutorando do Departamento de Zootecnia - Universidade Federal de Viçosa. Bolsista da CAPES.

2 Departamento de Zootecnia - Universidade Federal de Viçosa.
}

RESUMO - Avaliou-se a variabilidade espacial e temporal de características descritoras da condição de pastos diferidos de Brachiaria decumbens cv. Basilisk (capim-braquiária). Os tratamentos consistiram de combinações dos períodos de diferimento da pastagem (73, 103, 131 e 163 dias) com os períodos de pastejo (29, 57 e 85 dias). Utilizou-se esquema de parcelas subdivididas e delineamento em blocos casualizados com duas repetições. Foi determinada a dispersão dos valores de altura do pasto, altura da planta estendida e do índice de tombamento do pasto. A variabilidade espacial da altura do pasto aumentou de forma linear com o período de diferimento, porém não foi influenciada pelo período de pastejo. O coeficiente de variação da altura da planta estendida diminuiu linearmente em pastos submetidos aos maiores períodos de diferimento e não foi afetado pelo período de pastejo. A variabilidade do índice de tombamento, no entanto, apresentou resposta quadrática ao período de diferimento, com ponto de máximo correspondente ao coeficiente de variação de 38,25\% aos 130 dias. Em pastagens diferidas por curto período (73 dias), ocorreu variação negativa do coeficiente de variação durante o período de pastejo. Pastos de capimbraquiária sob diferimento por longos períodos possuem maior variabilidade da altura do pasto e menor heterogeneidade da altura da planta estendida. Além do efeito temporal, ocorre grande variabilidade espacial nas pastagens de capim-braquiária diferidas.

Palavras-chave: Brachiaria decumbens, coeficiente de variação, índice de tombamento, período de diferimento

\section{Spatial and temporal variability of vegetation on deferred signalgrass pastures}

\begin{abstract}
It was evaluated spatial and temporal variability of status descriptive characters of Brachiaria decumbens (signalgrass) cv. Basilisk deferred pastures. Treatments consisted of combinations of pasture deferring periods (73, 103, 131 and 163 days) with grazing periods (29, 57 and 85 days). Randomized block design with two repetitions and subdivided plots was used. It was determined the dispersion of pasture height (PH), stretched plant height (SPH) and falling index (FI) values. Pasture height spatial variability increased linearly with the deferring period, although it was not influenced by the grazing period. The coefficient of variation of stretched plant height decreased linearly on pastures subjected to longer deferring periods, and it was not affected by the grazing period. However, falling index variability showed a quadratic response to the deferring period, with maximum range corresponding to the coefficient of variation of $38.25 \%$ on the $130^{\text {th }}$ day. On pastures deferred for short periods (73 days), negative variation of the coefficient of variation was revealed during the grazing period. Brachiaria decumbens pastures under longer deferring periods have higher pasture height variability and lower stretched plant height heterogeneity. Besides the temporal effect, high spatial variability occurs on Brachiaria decumbens deferred pastures.
\end{abstract}

Key Words: Brachiaria decumbens, coefficient of variation, deferring period, falling index

\section{Introdução}

A utilização de pastagens diferidas para reduzir os efeitos negativos da sazonalidade produtiva das gramíneas forrageiras constitui estratégia de fácil adoção bastante utilizada pelos pecuaristas brasileiros. Para esse fim, a Brachiaria decumbens cv. Basilisk é apropriada, pois possui, entre outras características, colmo fino e boa produção durante o outono.
Um dos fatores determinantes da quantidade e qualidade da forragem produzida, bem como da estrutura do pasto, é o período de diferimento da pastagem. Dessa forma, é importante avaliar os efeitos do período de diferimento sobre as características descritoras do pasto, como altura e índice de tombamento (Santos et al., 2009), uma vez que sua estrutura influencia, concomitantemente, a produção vegetal e a produção animal (Carvalho et al., 2001).

Recebido em 10/11/2008 e aprovado em 16/4/2009.

Correspondências devem ser enviadas para:m_rozalino@yahoo.com.br 
Por outro lado, as pesquisas para caracterizar a estrutura dos pastos são predominantemente relativas às variações verticais do relvado, ou seja, caracterizam a forma como a forragem é disponibilizada desde o topo até sua parte inferior. Contrariamente, a frequente variação na estrutura horizontal criada pelo animal no decorrer do tempo geralmente não é avaliada. Contudo, a estrutura horizontal é importante em todas as escalas da interação planta-animal, enquanto a vertical tem relevância em escalas menores dessa interação (Carvalho et al., 2001).

Portanto, a vegetação existente numa pastagem é, por natureza, espacialmente heterogênea. Mesmo em pastos monoespecíficos, existe grande amplitude nos valores das características descritoras da condição do pasto, como altura, massa de forragem e número de perfilhos. Essa variabilidade espacial do pasto pode ser quantificada pelo coeficiente de variação dos valores de suas características descritoras (Hirata, 2002). A dinâmica dessa variabilidade espacial com o tempo pode ser compreendida pela elaboração de gráficos de frequências (Barthram et al., 2005).

Não há informações na literatura sobre a estrutura horizontal de pastagens tropicais diferidas. Assim, desenvolveu-se este trabalho com o objetivo de avaliar a variabilidade espaço-temporal de características descritoras da condição de pastos de Brachiaria decumbens cv. Basilisk diferidos.

\section{Material e Métodos}

O experimento foi conduzido no Setor de Forragicultura da Universidade Federal de Viçosa em pastagem de Brachiaria decumbens Stapf. cv. Basilisk (capimbraquiária) estabelecida em 1997. A pastagem foi dividida em oito piquetes com 0,25 a 0,40 ha. O clima, pelo sistema de Köppen (1948), é do tipo cwa, com estações seca (maio a outubro) e chuvosa (novembro a abril) bem definidas. A precipitação pluvial média anual é de 1.340 mm, com umidade relativa média do ar de $80 \%$ e temperatura média anual de $19^{\circ} \mathrm{C}$, com a média das máximas de $22,1^{\circ} \mathrm{C}$ e a média das mínimas de $15^{\circ} \mathrm{C}$ (Tabela 1 ).

O solo da área experimental, classificado como Latossolo Vermelho-Amarelo, de textura argilosa e com relevo medianamente ondulado, apresentou as seguintes características químicas na camada $0-20 \mathrm{~cm}$, em amostragem realizada no dia 17 de dezembro de 2003: $\mathrm{pH}$ em $\mathrm{H}_{2} \mathrm{O}$ : 5,0; P: 2,44(Mehlich-1) e K:98,13mg/dm ${ }^{3} ; \mathrm{Ca}^{2+}: 2,45 ; \mathrm{Mg}^{2+}: 0,56$ e $\mathrm{Al}^{3+}: 0,16 \mathrm{cmol}_{\mathrm{c}} / \mathrm{dm}^{3}(\mathrm{KCl} 1 \mathrm{~mol} / \mathrm{L})$. Nas datas de início dos diferimentos, foram aplicados em cada piquete $70 \mathrm{~kg} / \mathrm{ha}$ de nitrogênio na forma de ureia em cobertura.
Tabela 1 - Temperatura média diária, insolação e precipitação pluvial durante o período experimental (janeiro a setembro de 2005)

\begin{tabular}{lccc}
\hline Mês & $\begin{array}{c}\text { Temperatura } \\
\text { média do ar }\left({ }^{\circ} \mathrm{C}\right)\end{array}$ & $\begin{array}{c}\text { Insolação } \\
\text { (horas/dia) }\end{array}$ & $\begin{array}{c}\text { Precipitação } \\
\text { pluvial (mm) }\end{array}$ \\
\hline Janeiro & 22,7 & 4,3 & 203,1 \\
Fevereiro & 22,2 & 6,3 & 200,2 \\
Março & 22,6 & 5,2 & 267,5 \\
Abril & 21,4 & 6,0 & 57,6 \\
Maio & 18,7 & 6,0 & 45,0 \\
Junho & 17,0 & 4,9 & 32,7 \\
Julho & 15,8 & 6,0 & 24,5 \\
Agosto & 17,9 & 6,7 & 37,4 \\
Setembro & 19,6 & 3,2 & 67,5 \\
\hline
\end{tabular}

Fonte: Estação Meteorológica do Departamento de Engenharia Agrícola da UFV.

Os tratamentos consistiram das combinações de quatro períodos de diferimento da pastagem com três períodos de pastejo. O delineamento foi em blocos casualizados, com esquema de parcelas subdivididas e duas repetições. Os períodos de diferimento foram casualizados às parcelas. As subparcelas consistiram de medidas ao longo do período de pastejo, dentro de cada período de diferimento, separadamente. Os períodos de diferimento foram de 73, 103, 131 e 163 dias e, para sua implementação, os piquetes foram diferidos em épocas distintas (25/4/2005, 26/3/2005, 26/2/2005 e 25/1/2005), com mesma data de início do pastejo (7/7/2005). Os períodos de pastejo foram de 29, 57 e 85 dias e corresponderam às ocasiões em que as avaliações foram realizadas na pastagem, ou seja, a partir do 29 o dia de pastejo e repetidas a cada 28 dias, até o término do experimento (29/9/2005).

De novembro de 2004 até as datas de início dos diferimentos, todos os piquetes foram manejados sob lotação contínua, com taxa de lotação variável, a fim de manter as alturas dos pastos em aproximadamente $20 \mathrm{~cm}$. Todos os piquetes permaneceram diferidos até o dia 7 de julho, quando teve início o período de pastejo. As pastagens foram manejadas sob lotação contínua com taxa de lotação fixa e semelhante (3,4; 3,7 e 3,8 UA/ha nos meses de julho, agosto e setembro, respectivamente). Foram utilizados bovinos machos não-castrados, mestiços, com peso médio inicial de $190 \mathrm{~kg}$. Durante o período de pastejo, os animais receberam mistura múltipla de baixo consumo. As pastagens diferidas por 103, 121, 146 e 163 dias apresentaram oferta média de forragem correspondente a 3,46; 3,75; 4,41 e 5,23 kg de massa seca de forragem por kg de peso animal, respectivamente.

A altura do pasto em cada ponto foi determinada utilizando-se régua graduada e teve como critério a distância entre parte da planta localizada mais alta no dossel e o nível do solo. A altura da planta estendida foi mensurada estendendo-se os perfilhos da gramínea no sentido vertical 
e anotando-se a maior distância do nível do solo até o ápice dos perfilhos. Para estimar de forma objetiva o grau de acamamento dos pastos diferidos, foi criado o índice de tombamento do pasto, obtido pelo quociente entre a altura da planta estendida e a altura do pasto. Essas avaliações foram feitas em um caminhamento em zig-zag pelos piquetes, mensurando-se 50 pontos por unidade experimental. Já a avaliação da dispersão dessas medidas foi feita por meio do seu coeficiente de variação (Hirata, 2002).

A análise dos dados experimentais foi feita usando o Sistema para Análises Estatísticas - SAEG, versão 8.1 (Universidade Federal de Viçosa, 2003). Para cada característica, foi realizada análise de variância e, posteriormente, análise de regressão, cujo maior modelo de superfície de resposta em função das médias dos tratamentos foi o seguinte:

$$
Y_{i}=\beta_{0}+\beta_{1} D_{i}+\beta_{2} P_{i}+\beta_{3} D_{i} P_{i}+e_{i}
$$

em que: $\mathrm{Y}_{\mathrm{i}}=$ variável-resposta; $\mathrm{D}_{\mathrm{i}}$ = período de diferimento; $\mathrm{P}_{\mathrm{i}}=$ período de pastejo; $\beta_{0}, \beta_{1}, \beta_{2}, \beta_{3}=$ parâmetros a serem estimados; $\mathrm{e}_{\mathrm{i}}=$ erro experimental.

O grau de ajustamento dos modelos foi avaliado pelo coeficiente de determinação e pela significância dos coeficientes de regressão, testada pelo teste $\mathrm{t}$ corrigido com base nos resíduos da análise de variância.

Foram calculadas as variações percentuais dos coeficientes de variação das medidas de altura do pasto, altura da planta estendida e índice de tombamento entre o início e o término do período de pastejo nas pastagens de capim-braquiária diferidas por curto (73 dias) ou longo (163 dias) período. Os valores foram comparados pelo teste F a 5\% de probabilidade de ocorrência do erro tipo I.

Também foram gerados gráficos de frequência relativa para melhor visualização da dinâmica de variação espacial da altura e do índice de tombamento do pasto. As análises estatísticas foram realizadas ao nível de significância de até $10 \%$ de probabilidade.

\section{Resultados e Discussão}

A variabilidade espacial da altura do pasto, caracterizada pelo coeficiente de variação, aumentou de forma linear $(\mathrm{P}<0,05)$ com o período de diferimento da pastagem, porém não foi influenciada $(\mathrm{P}>0,10)$ pelo período de pastejo (Figura 1). Nas pastagens diferidas por maior período, a oferta de forragem foi elevada e, nessa condição, os bovinos tendem a concentrar sua atividade de pastejo em determinadas áreas da pastagem e, ao mesmo tempo, rejeitar outras. Dessa maneira, há maior probabilidade de as desfolhações ocorrerem nos locais previamente pastejados, resultando em maior heterogeneidade espacial da vegetação (Hodgson, 1990).

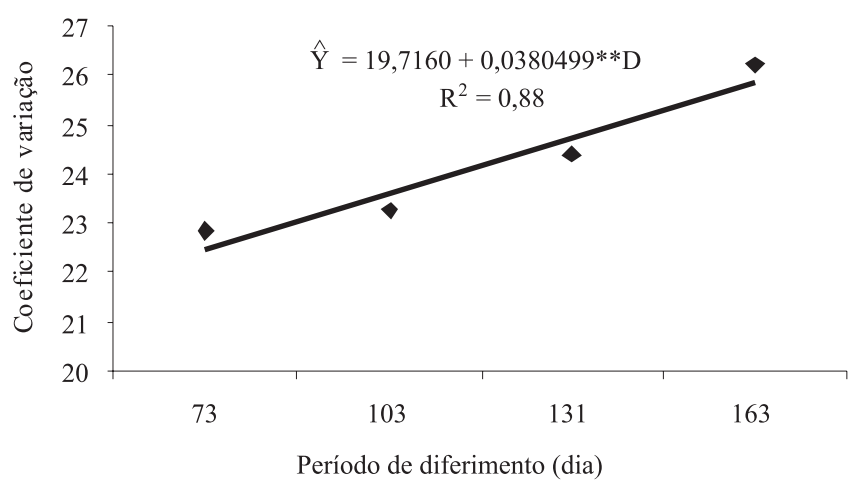

**Significativo pelo teste $\mathrm{t}(\mathrm{P}<0,05)$.

Figura 1 - Coeficiente de variação da altura do pasto em função do período de diferimento da pastagem de capim-braquiária.

Além disso, os pastos sob maior período de diferimento apresentaram maior frequência de áreas com elevado índice de tombamento das plantas. Quando ocorre o tombamento das plantas, a altura do pasto diminui e isso contribui para elevar a variabilidade da altura do pasto. Esse resultado corrobora aqueles obtidos por Braga et al. (2004) em pastos de Brachiaria brizantha cv. Marandu manejados em lotação intermitente sob ofertas de forragem. Segundo esses autores, houve intenso tombamento das plantas nas pastagens submetidas à oferta de forragem de $20 \%$, o que contribuiu para o aumento da variabilidade espacial da altura do pasto.

Por outro lado, o coeficiente de variação da altura da planta estendida diminuiu linearmente $(\mathrm{P}<0,01)$ em pastos submetidos aos maiores períodos de diferimento e não foi influenciado pelo período de pastejo (Figura 2). Em todos os pastos diferidos, ocorreram perfilhos vegetativos e reprodutivos, e os reprodutivos eram de maior comprimento.

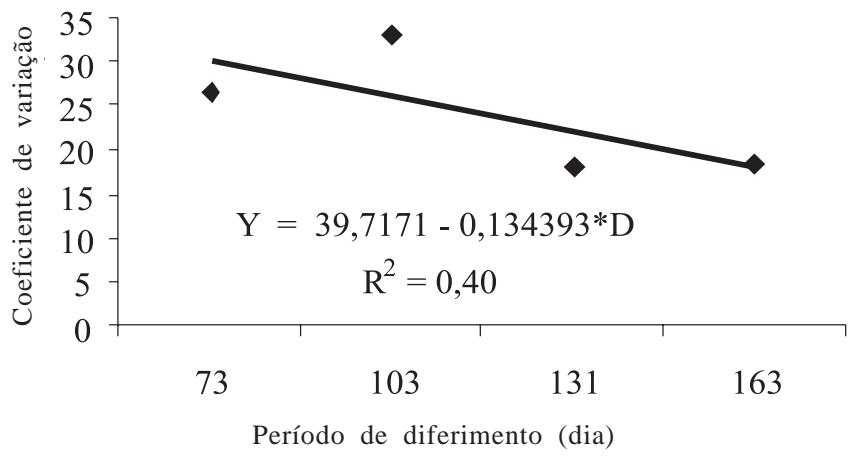

*Significativo pelo teste $\mathrm{t}(\mathrm{P}<0,10)$

Figura 2 - Coeficiente de variação da altura da planta estendida em função do período de diferimento da pastagem de capim-braquiária. 
Todavia, nos pastos diferidos por maior período, os perfilhos vegetativos também possuíam colmos compridos, semelhante ao dos reprodutivos, em razão de sua maior idade. Dessa forma, as plantas apresentaram maior uniformidade de altura quando seus perfilhos foram estendidos para medição da altura da planta estendida. Contrariamente, pastos sob menores períodos de diferimento continham perfilhos vegetativos mais jovens, com comprimento de colmo inferior ao dos perfilhos reprodutivos. Isso pode ter sido a causa da maior heterogeneidade da altura da planta estendida nos pastos sob menor período de diferimento, uma vez que áreas do pasto com perfilhos reprodutivos apresentaram maior altura da planta estendida, enquanto aquelas com predominância de perfilhos vegetativos foram de menor altura da planta estendida.

A variabilidade do índice de tombamento das plantas apresentou $(\mathrm{P}<0,05)$ resposta quadrática ao período de diferimento (Figura 3), com ponto de máximo correspondente ao coeficiente de variação de $38,25 \%$ aos 130 dias de diferimento da pastagem. Isso indica que a variabilidade das medidas de índice de tombamento do pasto foi menor quando impostos períodos de diferimento extremos. Pastos sob menor período de diferimento praticamente não possuíam plantas tombadas, daí a menor variabilidade de seus índices de tombamento. Já pastos diferidos por períodos demasiadamente longos foram caracterizados por plantas muito tombadas, situação em que o índice de tombamento foi alto e bastante uniforme. De outra forma, em pastos diferidos por períodos intermediários, a heterogeneidade dos valores de índice de tombamento foi alta, em razão da maior diversidade de áreas com e sem tombamento das plantas.

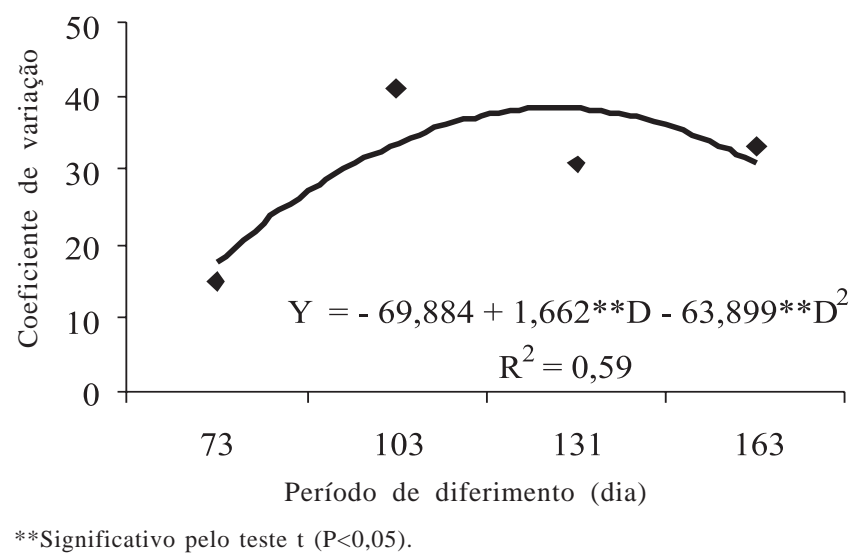

Figura 3 - Coeficiente de variação do índice de tombamento em função do período de diferimento da pastagem de capim-braquiária.
Considerando que a altura do pasto, a altura da planta estendida e o índice de tombamento do pasto estão fortemente associados a outras características descritoras da condição do pasto, como massa de forragem, e de seus componentes morfológicos (Santos et al., 2009), pode-se inferir que o período de diferimento da pastagem também modifica a variabilidade espacial dessas outras características.

Assim, independentemente do período de diferimento da pastagem, sempre houve variação espacial da vegetação, pois os coeficientes de variação nunca foram nulos (Figuras 1, 2 e 3). De fato, mesmo em pastos monoespecíficos, a distribuição heterogênea da vegetação é inevitável, porque a proporção de forragem removida a cada bocado do animal é consideravelmente maior que aquela que deveria ser removida para manter a uniformidade do pasto (Parsons \& Chapman, 2000), notadamente em pastos diferidos, que geralmente são utilizados durante o período de inverno, quando as condições climáticas são restritivas ao crescimento da planta.

Outros fatores que podem explicar a heterogeneidade dos pastos diferidos são os gradientes de fertilidade e de umidade do solo na área da pastagem. De fato, as condições de oferta de recursos tróficos no plano horizontal também resultam em variação espacial da vegetação (Carvalho et al., 2001). Em geral, nas áreas de maior fertilidade e umidade, a forrageira cresce mais rápido e possui maior altura da planta estendida, portanto, é maior a possibilidade de ocorrência de tombamento das plantas. Já nas áreas de baixa fertilidade e com menor disponibilidade hídrica, o padrão de resposta tende a ser contrário.

Neste trabalho, mesmo adotando o delineamento em blocos para controle da variação no relevo da área experimental, alguns piquetes apresentavam certa declividade. Como geralmente existe significativa associação entre relevo e fertilidade do solo, bem como entre relevo e umidade do solo, é provável que áreas da pastagem localizadas nas regiões mais altas possuíssem baixa fertilidade e menor disponibilidade hídrica, em comparação às áreas localizadas nas regiões mais baixas; e isso certamente afetou o desenvolvimento da planta de forma diferenciada, contribuindo para a variação espacial da vegetação.

Pode-se inferir também que a variabilidade espacial dos valores de altura do pasto, altura da planta estendida e índice de tombamento resulta em microclimas diferenciados (temperatura, ventilação, luminosidade, etc) na área da pastagem diferida, que, certamente, irão influenciar de forma heterogênea processos intrínsecos e importantes no 
ecossistema pastagem, como crescimento, senescência e perfilhamento. Isso faz com que a heterogeneidade do pasto persista por maior período, contribuindo para sua inerente e dinâmica variabilidade horizontal.

Em pastagens diferidas por curto período (73 dias), a variabilidade espacial da vegetação diminuiu após o período de pastejo (variação negativa do coeficiente de variação). Contrariamente, a variabilidade aumentou nos pastos diferidos por longo período (163 dias), com exceção da altura da planta estendida (Figura 4). Esses resultados indicam que o conceito de proporcionalidade entre profundidade do bocado e altura do pasto (Prache \& Peyraud, 2001) não ocorreu, já que o coeficiente de variação da altura do pasto durante o período de pastejo mostrou-se variável.

Os pastos sob diferimento por 73 dias apresentaram menor variação percentual do coeficiente de variação altura do pasto em comparação àqueles sob 173 dias de diferimento $(\mathrm{P}<0,05)$ durante o período de pastejo. A variabilidade da altura do pasto foi negativa nos pastos diferidos por 73 dias e positiva naqueles diferidos por 163 dias (Figura 4). Na condição de diferimento por 73 dias, a altura média do pasto foi maior no início do período de pastejo em relação ao final desse período. Dessa forma, é natural que a variabilidade da altura do pasto tenha reduzido com o pastejo, pois geralmente pastos mais baixos possuem vegetação mais homogênea. Nesse sentido, Schwartz et al. (2003) concluíram que, em média, quanto maior a altura do pasto de milheto (Pennisetum americanum Leeke), maior sua heterogeneidade.

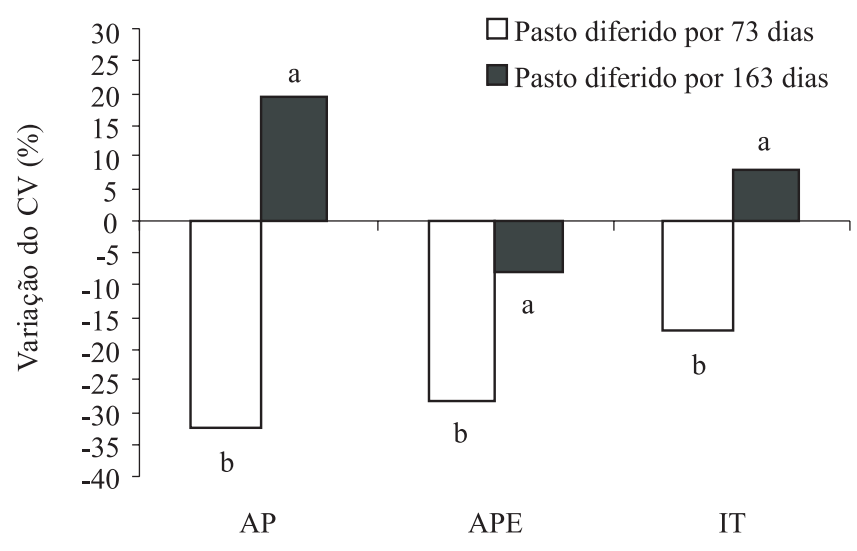

Para cada característica, letras diferentes diferem pelo teste $\mathrm{F}(\mathrm{P}<0,05)$.

Figura 4 - Variação percentual do coeficiente de variação (CV) das medidas de altura do pasto (AP), altura da planta estendida (APE) e índice de tombamento (IT) entre o início e o final do período de utilização de pastos de capim-braquiária diferidos por 73 e 163 dias.
Já na condição de diferimento por 163 dias, a redução na altura do pasto com o pastejo foi menos intensa, uma vez que os pastos já se encontravam com plantas tombadas desde o início do período de pastejo. Além disso, nestas pastagens, a produção de forragem foi elevada, em virtude da maior idade das plantas. Com isso, os bovinos provalvemente tiveram maior oportunidade para expressar seu comportamento de pastejo seletivo, resultando em áreas com intensidade e frequência de pastejo desiguais na pastagem e, assim, maior variabilidade espacial da vegetação ao término do período de pastejo.

Embora negativa, a variabilidade da altura da planta estendida durante o período de pastejo também foi maior $(\mathrm{P}<0,05)$ na pastagem diferida por 163 dias em comparação àquela diferida por 73 dias (Figura 4). Nesta, praticamente não houve tombamento das plantas e os valores de altura da planta estendida foram próximos aos de altura do pasto. Desse modo, a heterogeneidade dos valores de altura da planta estendida também foi menor no término do período de pastejo (variação mais negativa do coeficiente de variação), semelhantemente ao ocorrido com a altura da planta.

Durante o período de pastejo, a variação da heterogeneidade espacial das medidas de índice de tombamento foi maior $(\mathrm{P}<0,05)$ nos pastos diferidos por 163 dias em comparação àqueles diferidos pr 73 dias (Figura 4). Pastos sob maior período de diferimento (163 dias) foram caracterizados por maior oferta de forragem e, nessa condição, é provável que a maturidade das plantas na pastagem tenha sido mais diversificada (Stuth et al., 1981), o que pode ter contribuído para a maior variação no índice de tombamento do pasto no decorrer do período de pastejo. De fato, nas áreas do pasto diferido onde as plantas eram mais desenvolvidas, o tombamento foi maior com o pastejo animal, contrariamente ao observado nas áreas com plantas menos desenvolvidas. Por outro lado, em pastos sob menor período de diferimento (73 dias), houve menor oferta de forragem e estádio de maturidade das plantas mais uniforme, uma vez que eram mais jovens e, por isso, menos susceptíveis ao tombamento durante o pastejo.

Os dados de variabilidade percentual do coeficiente de variação entre o início e o término do período de pastejo em pastagens diferidas indicam que a variação espacial da vegetação não é estática, mas dinâmica durante o tempo. Além disso, ações de manejo da pastagem, como a duração do período de diferimento, influenciam essa heterogeneidade do pasto no decorrer do tempo. Outros fatores também modificam a variabilidade espacial da vegetação, como estação do ano, taxa de lotação e método de pastejo (Cid \& Brizuela, 1998). 
O caráter dinâmico da variabilidade espacial das características descritoras do pasto tem como consequência maior dificuldade na predição de estimativas de desempenho ou produção animal. Assim, quanto maior a variação espacial da vegetação, mais complexa e difícil é a estimativa de produção animal e, nesse contexto, pesquisas têm sido realizadas para quantificar, por exemplo, a variabilidade de alguns critérios de manejo do pastejo, no intuito de recomendar aquele de menor variabilidade (Schwartz et al., 2003).

A altura do pasto diferido apresentou elevada magnitude de variação dos coeficientes de variação entre o início e o término do período de pastejo, caracterizando a dinâmica temporal desta característica em pastos diferidos. Com isso, a altura do pasto não deve ser recomendada como característica descritora da condição do pasto diferido quando o objetivo for realização de estimativa do desempenho animal. Por outro lado, menor variabilidade dos coeficientes de variação durante o período de pastejo foi constatada para o índice de tombamento do pasto (Figura 4). A dinâmica espacial e temporal da variabilidade espacial da altura e do índice de tombamento do pasto entre os períodos de diferimento e de pastejo também pode ser verificada pela frequência relativa de seus valores (Figuras 5, 6, 7 e 8).

As classes de altura do pasto 3 e 4, correspondentes aos valores de 10 a 19,9 cm e de 20 a 29,9 cm, respectiva-
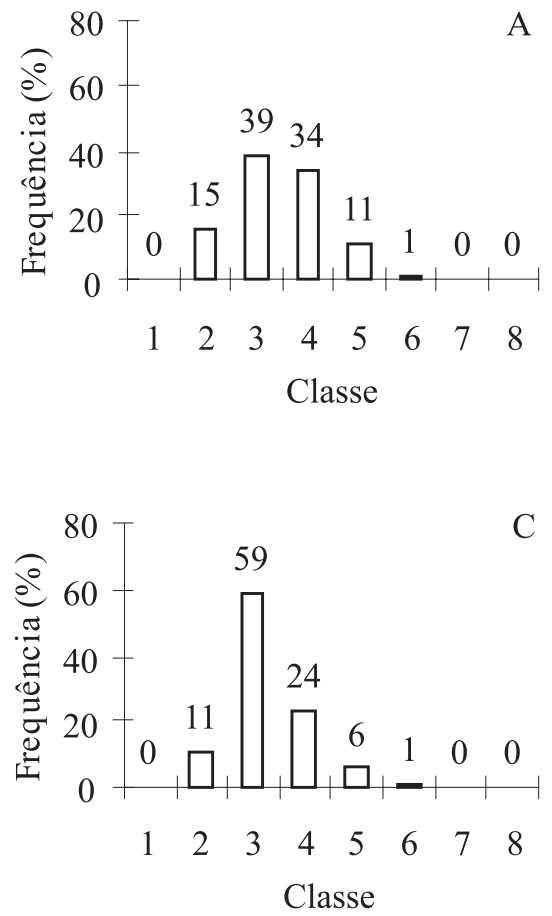

mente, foram mais frequentes nos pastos, independentemente dos períodos de diferimento. Entretanto, essas classes tiveram pequeno aumento com o período de diferimento da pastagem (de 73\% para 80\%). A frequência da classe 2 (10 a 19,9 cm) diminuiu de 15 para 9\% durante o período de pastejo (Figura 5). Com o aumento do período de diferimento, houve aumento no número de classes (de 5 para 6), e maior concentração dos valores de altura do pasto nas classes 3 e 4, comprovando maior disparidade dos valores de altura do pasto com o período de diferimento, o que justifica a elevação da heterogeneidade dessa característica (Figura 1).

O índice de tombamento apresentou alteração na classe de maior frequência relativa com o período de diferimento da pastagem (Figura 6). Nos pastos diferidos por 73 dias, 93\% dos índices de tombamento foram de 1,0 a 1,8 de (classe 2). Nos pastos sob 103 dias de diferimento, essa classe diminuiu sua participação para $70 \%$ dos valores de índice de tombamento medidos e esses valores reduziram ainda mais nos pastos sob maior período de diferimento (173 dias), cuja frequência relativa era de apenas $7 \%$ para a classe 2. Por outro lado, verificou-se acentuado aumento nas classes 4 (de 2,8 a 3,6) e 5 (de 3,7 a 4,5) com a elevação do período de diferimento (de 1 para $28 \%$ e de 0 para $26 \%$, respectivamente, para as classes 4 e 5). Isso comprova que o tombamento das plantas foi mais intenso nos pastos
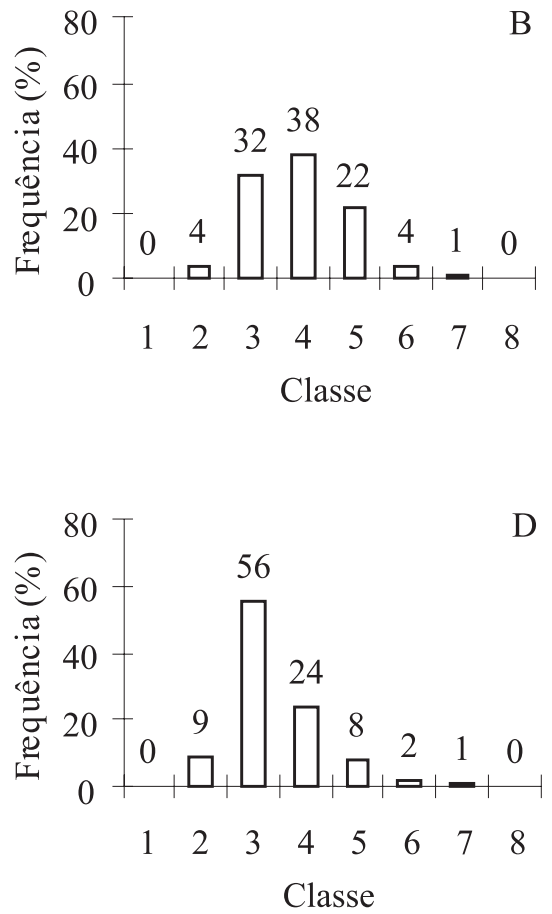

*Classes de altura do pasto: 1 = até $9,9 \mathrm{~cm} ; 2$ = de 10 a 19,9 cm; 3 = de 20 a $29,9 \mathrm{~cm} ; 4$ = de 30 a 39,9 cm; 5 = de 40 a $49,9 \mathrm{~cm} ; 6=$ de 50 a $59,9 \mathrm{~cm} ; 7$ = de 60 a $69,9 \mathrm{~cm}$; $7=$ de $70 \mathrm{a} 80 \mathrm{~cm}$.

Figura 5 - Frequência relativa (\%) da altura do pasto de capim-braquiária em pastagens diferidas por 73 (A), 103 (B), 131 (C) e 163 (D) dias. 

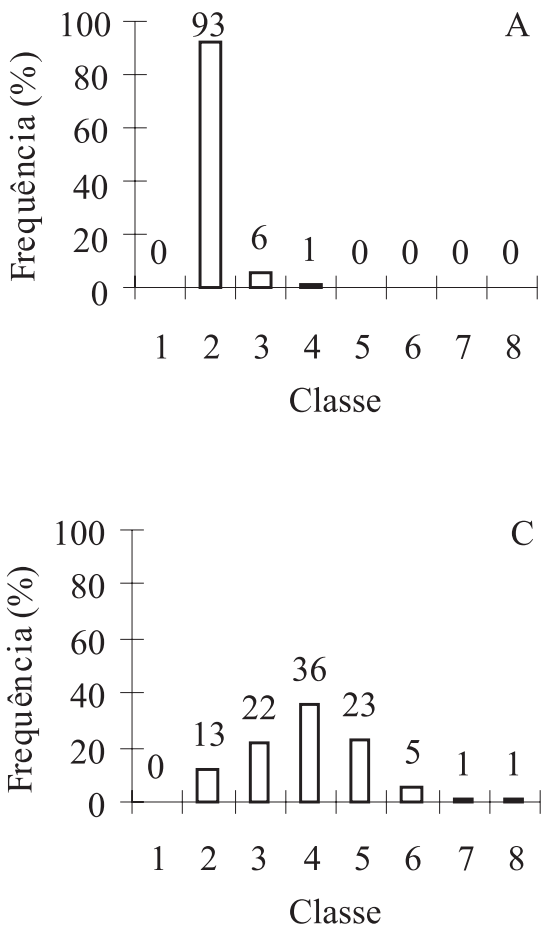

$\mathrm{B}$
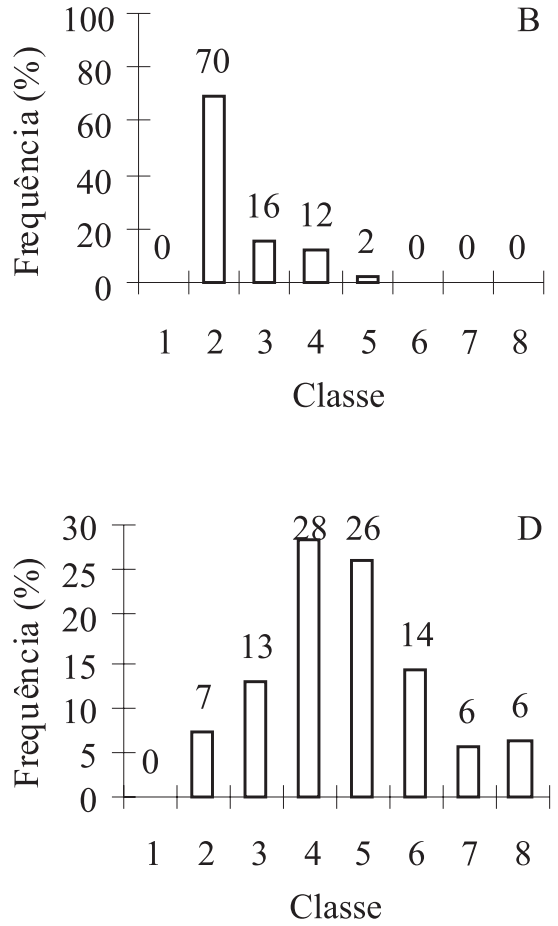

*Classes de índice de tombamento do pasto: $1=$ até 0,$9 ; 2=$ de 1,0 a 1,$8 ; 3=$ de 1,9 a 2,$7 ; 4=$ de 2,8 a 3,$6 ; \quad 5=$ de 3,7 a 4,$5 ; 6=$ de 4,6 a 5,$4 ; 7=$ de 5,5 a 6,$3 ; 7=$ de 6,4 a 7,2 .

Figura 6 - Frequência relativa (\%) do índice de tombamento do pasto de capim-braquiária diferidos por 73 (A), 103 (B), 131 (C) e 163 (D) dias.
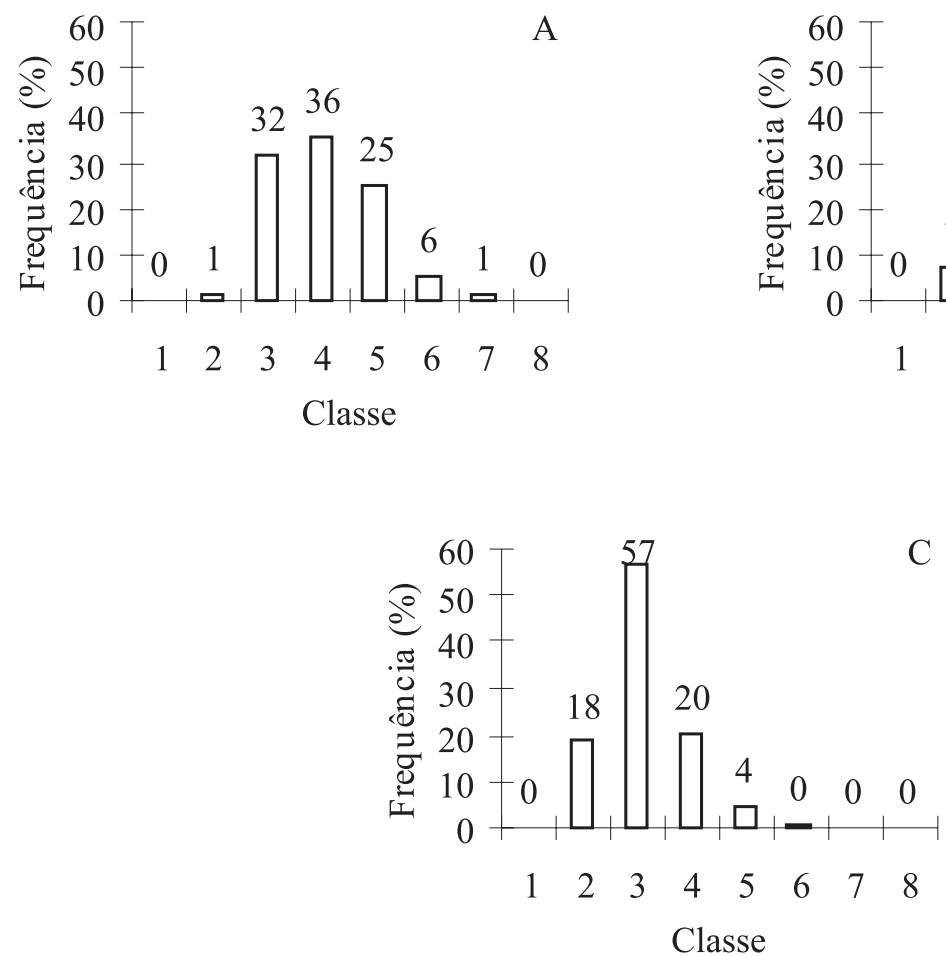

*Classes da altura do pasto: 1 = até $9,9 \mathrm{~cm} ; 2$ = de 10 a 19,9 cm; $3=$ de 20 a $29,9 \mathrm{~cm} ; 4$ = de 30 a $39,9 \mathrm{~cm} ; 5=$ de 40 a $49,9 \mathrm{~cm} ; 6=$ de 50 a $59,9 \mathrm{~cm} ; 7$ = de 60 a $69,9 \mathrm{~cm}$; $7=$ de 70 a $80 \mathrm{~cm}$.

Figura 7 - Frequência relativa (\%) da altura dos pastos diferidos de capim-braquiária após 29(A), 57 (B) e 85 (C) dias do início do período de utilização das pastagens.

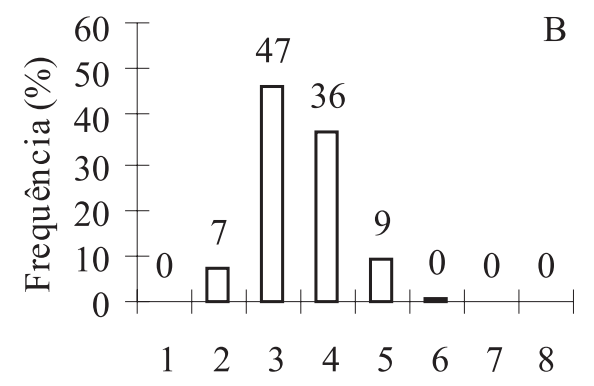

Classe 
diferidos por maior período. Além disso, aumentou o número de classes de índice de tombamento foi verificado até 131 dias de diferimento, o que permite inferir que a heterogeneidade do pasto aumentou até este ponto.

No decorrer do período de pastejo, houve maior participação das classes 2 (10,0 a 19,9 cm) e 3 (20 a 29,9 $\mathrm{cm})$ de altura do pasto e decréscimo nas classes 4 (30,0 a 39,9 cm) e 5 (40,0 a 49,9 cm), evidenciando redução da altura do pasto com o período de pastejo (Figura 7). Além disso, aos 29 dias de pastejo, havia seis classes de altura do pasto, que diminuíram para quatro no último dia de pastejo (85 dias). Entretanto, nesse dia, os valores de altura do pasto foram mais discrepantes. Esses resultados explicam a ausência de efeito do período de pastejo sobre a heterogeneidade da altura do pasto, pois o maior número de classes verificado no início do período de pastejo, que é indicador de variabilidade, foi compensado pela maior discrepância dos dados no último dia do período de pastejo.

Durante o período de pastejo, a frequência relativa da classe 2 (de 1,0 a 1,8 ) diminuiu (de 50 para $18 \%$ ) e a da classe 3 (de 1,9 a 2,7) aumentou (de 14 para $20 \%$ ), indicando aumento das áreas do pasto com tombamento mais intenso das plantas (Figura 8).
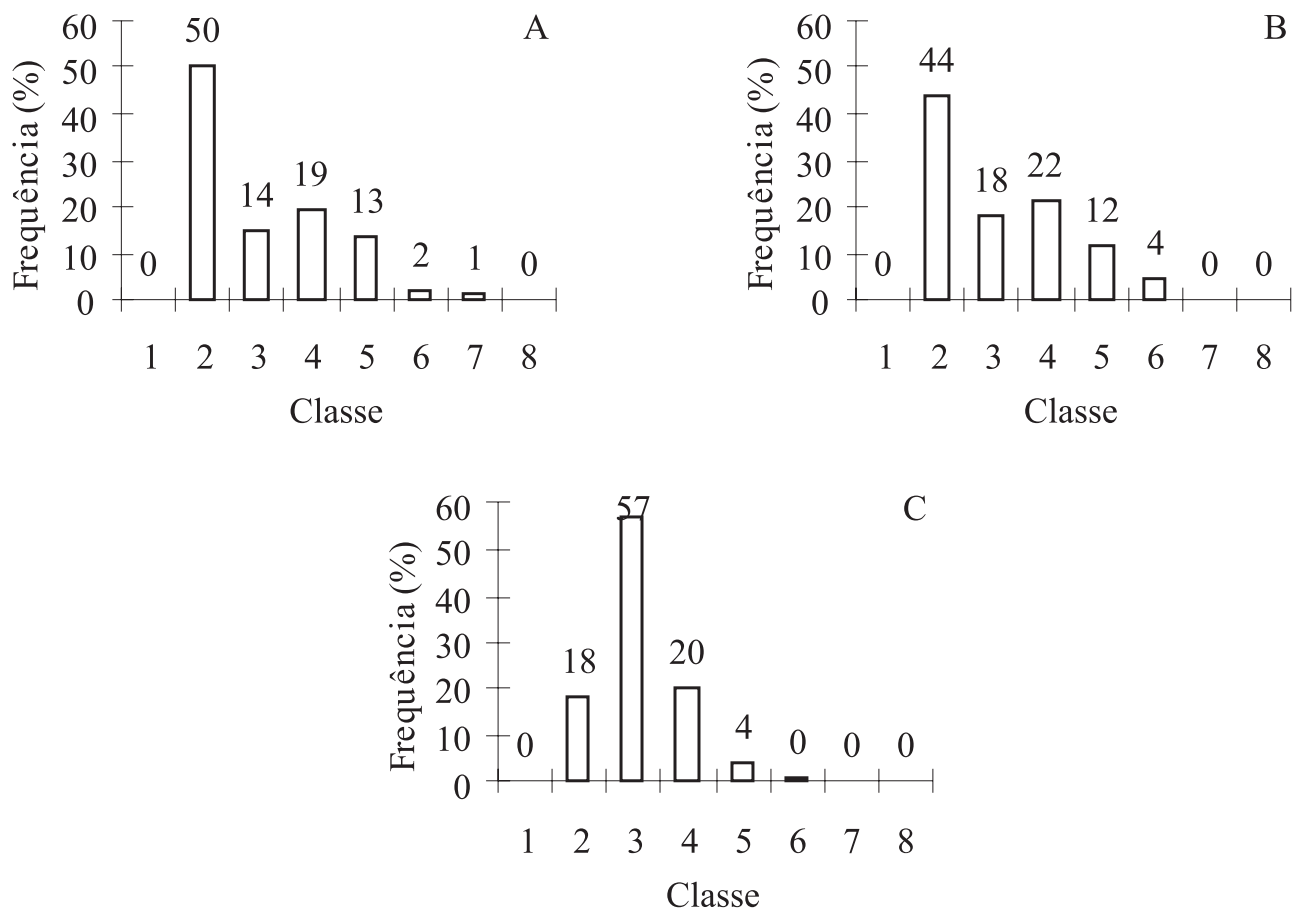

*Classes de índice de tombamento do pasto: $1=$ até 0,$9 ; 2=$ de 1,0 a 1,$8 ; 3=$ de 1,9 a 2,$7 ; 4=$ de 2,8 a 3,$6 ; 5=$ de 3,7 a 4,$5 ; 6=$ de 4,6 a 5,$4 ; 7=$ de 5,5 a 6,$3 ; 7=$ de 6,4 a 7,2 .

Figura 8 - Frequência relativa (\%) do índice de tombamento dos pastos diferidos de capim-braquiária após 29 (A), 57 (B) e 85 (C) dias do início do período de utilização das pastagens.

\section{Conclusões}

Existe variabilidade espacial e temporal em pastos de Brachiaria decumbens cv. Basilisk diferidos. Maiores períodos de diferimento proporcionam maior variabilidade na altura do pasto e menor heterogeneidade na altura da planta estendida. Nos pastos diferidos por períodos intermediários, a heterogeneidade dos valores de índice de tombamento é maior. Em pastagem diferida por período curto (73 dias), a variabilidade espacial da vegetação diminui durante o pastejo em comparação à pastagem diferida por 163 dias.

\section{Referências}

BARTHRAM, E.; DUFF, G.T.I.; ELSTON, D.A. et al. Frequency distributions of sward height under sheep grazing. Ltd. Grass and Forage Science, v.60, p.4-16, 2005.

BRAGA, G.J.; PEDREIRA, C.G.S.; HERLING, V.R. et al. Eficiência de pastejo de capim-marandu submetido a diferentes ofertas de forragem. Pesquisa Agropecuária Brasileira, v.49, n.11, p.1641-1649, 2007. 
CARVALHO, P.C.F.; RIBEIRO FILHO, H.M.N.; POLI, C.H.E.C. et al. Importância da estrutura da pastagem na ingestão e seleção de dietas pelo animal em pastejo. In: REUNIÃO ANUAL DA SOCIEDADE BRASILEIRA DE ZOOTECNIA, 38., 2001, Piracicaba. Anais... Piracicaba: ESALQ, 2001. p.883-871.

CID, M.S.; BRIZUELA, M.A. Heterogeneity in tall fescue pastures created and sustained by cattle grazing. Journal of Range Management, v.51, p.644-649, 1998.

HIRATA, M. Herbage availability and utilisation in small-scale patches in a bahia grass (Paspalum notatum) pasture under cattle grazing. Tropical Grasslands, v.36, p.13-23, 2002.

HODGSON, J. Grazing management - science into practice. Essex: Longman Scientific \& Technical, 1990. 203p.

KÖPPEN, W. Climatologia. Buenos Aires: Panamericana, 1948. 478p.

PARSONS, A.J.; CHAPMAN, D.F. The principles of pasture growth and utilization. In: HOPKINS, A. (Ed.). Grass: its production and utilization. London: CAB International, 2000. p.31-89.

PRACHE, S.; PEYRAUD, J.L. Foraging behaviour and intake in temperate cultivated grasslands. In: INTERNATIONAL GRASSLAND CONGRESS, 19., São Pedro, 2001.
Proceedings... Piracicaba: Fundação de Estudos Agrários Luiz de Queiroz, 2001. p.309-319.

SANTOS, M.E.R.; FONSECA, D.M.; EUCLIDES, V.P.B. et al. Características estruturais e índice de tombamento de Brachiaria decumbens cv. Basilisk em pastagens diferidas. Revista Brasileira de Zootecnia, v.38, n.4, p.626-634, 2009.

SCHWARTZ, F.; ROCHA, M.G.; VÉRAS, M. et al. Manejo de milheto (Pennisetum americanum Leeke) sob pastejo de ovinos. Revista Brasileira Agrociência, v.9, n.2, p.151-155, 2003.

STOBBS, T.H. The effect of plant structure on the intake of tropical pastures.III. Influence of fertilizer nitrogen on the variation in the bite size of bite harvested by jersey cows grazing Setaria anceps cv. Kazungula swards. Australian Journal of Agricultural Research, v.26, p.997-1007, 1975.

STUTH, J.W.; KIRBY, D.R.; CHMIELEWSKI, R.E. Effect of herbage allowance on the efficiency of defoliation by the grazing animal. Grass and Forage Science, v.36, p.9-15, 1981.

UNIVERSIDADE FEDERAL DE VIÇOSA - UFV. SAEG - Sistema de análises estatísticas e genéticas. Versão 8.1. Viçosa, MG: 2003. (Apostila). 